\title{
GENETIC ENGINEERING AND BIOTECHNOLOGY FIRMS
}

Genetic Engineering and Biotechnology Firms Worldwide Directory 1983/1984. Edited by M. Sittig and R. Noyes. Pp. 427. (Sittig and Noyes, Kingston, N.J.: 1983) \$177

Gor a relatively new industry, bioTechnology is remarkably well served with information sources. Few researchers or managers can have failed to notice the recent boom in journal, newsletter, and book publishing, but it is still difficult to choose the best and most cost effective works. This new directory ranks high among current offerings, but could still benefit from considerable improvement.

On the positive side it is reasonably well established, being now in its third edition. It is not too expensive: individual entries cost 15 cents each on the average, a significant decrease from previous editions which worked out at 28 cents each in 1982 and 38 cents in 1981. There are about 700 U.S. firms listed in 292 pages, plus about 500 foreign firms in 137 pages. Both sections include some research institutes, a number of publishers of biotechnology journals and market surveys, and many "traditional" antibiotics producers. Subsidiaries and investors are listed as separate entries. This adds relatively little to the overall usefulness of the directory, though of course it makes the cost per entry appear lower.

Individual entries vary greatly in length. Each contains an address (often quite incomplete for foreign firms) and a telephone number. Foreign telephone numbers are often absent and international codes are inconsistently handled, while all U.S. entries give the area code. No telex numbers are given. The remaining information often takes the form of one or two short notes (e.g. Has equity interest in Y, reported to be working on $\mathrm{X}$ ) but it may be as long as two pages. No personal contact names are provided.

Some of the entries are very out of date and incomplete, and few if any contain details of any activities after June 1983-many only cover 1982. Nevertheless it is probably about as up-to-date as either of the two other major annual biotechnology directories publshed in 1983 (The International Biotechnology Directory, 1984, Macmillan/Nature Press at $\$ 100$, and the
Genetic Engineering and Biotechnology Yearbook, 1983, Elsevier Biomedical at $\$ 750$ ). It has more long entries than either of these competitors but fewer listings overall and stronger U.S. bias. There is amazingly little overlap in content between the three directories, however, and the Sittig and Noyes directory does include some of the more obscure concerns not listed elsewhere.

The packaging is not impressivean A4 softbound typescript. Like previous editions our copy suffered from various niggling errors (pages duplicated, typographical errors, table on Cetus non-existent, etc.), but these were generally less severe than in previous years. There is no subject index, but there is an eight page

\section{FERMENTATION MANUAL FIZZLES}

Fermentation and Biochemical Engineering Handbook. Edited by Henry C. Vogel. Pp. 440. ISBN 0-81550950-2. (Noyes Publications, Park Ridge, NJ: 1983) \$64.00.

$A$ handbook, in the sense the editor A of this book presumably intended, is meant to be a book of instruction or guidance, a manual for a particular field. Purchasers of this book, who are no doubt looking for help in coming to grips with the engineering problems encountered in using biotechnology for industrial manufacturing, will find little relief in its pages. This is distressing, since a well executed handbook of industrial fermentation and associated processes is sorely needed by the biotechnology industry. The irony of a book on fermentation engineering of more than 400 pages, chapter after chapter of which is essentially devoid of any mention of biological concepts or processes, is probably unintended, but that is the case. It is true that several chapters either begin or end by mentioning fermentation, but such reference is only in passing.

The first four chapters focus on fermentation arts and biological processes. The first chapter is a competently written introduction to microbiology for engineers. It contains most of the major concepts enjoying currency in industrial microbiology, as well as an outline of the underlying introductory review with a limited bibliography.

Overall this directory is probably more suitable for purchase by corporate rather than academic libraries. It is too expensive to be a good value for most individuals and would benefit from a better presentation, but at the moment it is probably the least expensive, reasonably up-to-date source offering fairly detailed entries on U.S. biotechnology companies. It is unlikely to maintain that position for long, if other publishers update their previous offerings.

Anita Crafts-Lighty, Ph.D., is information manager at Celltech Limited, 244 Bath Road, Slough, U.K.

scientific principles. Needless to say, no claim to completeness can be made in 47 pages of text, but the attempt is readable. I would have liked the chapter to have been at least doubled in size to allow an introduction to the uses, that is, the applications of microbiology in an industrial setting: what products, specifically, are made commercially; what new products appear promising; and what future prospects make a handbook of biochemical engineering worth attempting?

The second chapter is a short description of the major features of a so-called "pilot plant" fermentor. The title of the chapter is "Industrial Pilot Plant," but all of the text is devoted to the fermentor and its operating features. The next chapter discusses fullscale fermentation plants. About 25 percent of the text describes the design of continuous sterilizers, a specialty of the author. Other sections discuss whether sparging more air or using more mechanical power input through higher agitation speeds is a more efficient means of increasing oxygen transfer rates in fermentors. The author doesn't seem sure.

In Chapter 4 we learn the fundamentals of agitation effects in fermentation vessels. The subject matter is covered in the manner we have come to expect from the author, who has written a recent monograph on fluid mixing technology, and who has 